Www.jmscr.igmpublication.org

Impact Factor (SJIF): 6.379

Index Copernicus Value: 79.54

ISSN (e)-2347-176x ISSN (p) 2455-0450

crossrefDOI: https://dx.doi.org/10.18535/jmscr/v6i10.136

Journal Of Medical Science And Clinical Research

IGM Publication

An official Publication of IGM Publication

\title{
Serum Creatine Kinase Levels in Overt and Subclinical Hypothyroidism
}

\author{
Authors \\ Dr Vikas ${ }^{1}$, Dr Gurdeep Kaur², Dr Neera Samar ${ }^{3}$, Dr Avinash Kulkarni ${ }^{4}$ \\ Dr Sanjay Parmar ${ }^{5}$, Dr Rohtash Gurjar ${ }^{6}$ \\ ${ }_{1,4,5,6}$ Resident, ${ }^{2,3}$ Professor \\ Department of Medicine R.N.T. Medical College, Udaipur, India
}

\begin{abstract}
Introduction: Aim of present study is to assess the relationship between thyroid function and creatine kinase in patients with overt and subclinical hypothyroidism and correlation with thyroid hormone levels.

Methodology: The study consists of 30 control, 30 overt and 30 subclinical primary hypothyroidism patients with females(81\%)>males (19\%) attending medicine and endocrine outdoor in R.N.T. Medical college after taking oral informed consent and applying inclusion and exclusion criteria.

Observations: The study showed statistically significant increase in creatine kinase in overt hypothyroidism and subclinical hypothyroidism (172.77) compared to controls (97.60)

Conclusion: A highly positive correlation is observed between TSH and CK activity ( $p$ value <0.001) in the present study which indicates the influence of TSH on muscles in hypothyroidism though the rise of CK activity is nearly 4 to 5 times more in overt cases.There is highly significant negative correlation between T3 and T4 level with CK activity in the present study indicative of predominant role of decreased $T 3$ and T4 level in overt cases in influencing this release of CK from skeletal muscles.
\end{abstract}

\section{Introduction}

Hypothyroidism is one of the most common endocrine disorders of the world resulting from insufficient production or diminished action of thyroid hormone. Thyroid hormone influences the function of all the organs in the body. Both hyper and hypothyroidism have shown to affect the neuromuscular system. This study is undertaken to study the muscle dysfunction in hypothyroid and subclinical hypothyroids by the evaluating the symptomatology and CPK level and correlating with thyroid hormone levels.

\section{Aim of the Study}

The aim of the present study is to assess the relationship between thyroid funtion and creatine kinase in patients with overt and subclinical hypothyroidism

\section{Objectives}

1. The objective of the study is to assess total creatine kinase activity in overt and subclinical hypothyroidism and thus demonstrate that muscle dysfunction starts early even during subclinical hypothyrodism

2. To investigate if there is correlation between thyroid stimulating (TSH), T3, $\mathrm{T} 4$, Creatine kinase levels and patients symptoms in overt and sub clinical hypothyroidism 


\section{Materials and Methods}

Study Type: Prospective and follow up 60 patients (30 clinical and 30 subclinical) attending OPD, IPD, Endocrinology outdoor at M.B.G Hospital, attached to R.N.T Medical college, Udaipur over a period of 1 year from Dec 2015 to Dec 2016 were included in study after proper informed consent.

\section{Inclusion Criteria}

- Age > 15 yr up to $75 \mathrm{yr}$

- Patients with TSH above normal range

\section{Exclusion Criteria}

- Patients with impaired renal function (creatinine $>1.4 \mathrm{mg} / \mathrm{dl}$ )

- Patients with ischemic heart disease and stroke

- Patients with rheumatoid arthritis and muscle disease
- Pregnant and lactating females

\section{Hormone level T3, T4, TSH}

Measured by electrochemical immunoassay "ECLIA" on Cobas -e immunoassay analyser

Test principle: Sandwich principle.

Total duration of assay: 18 minutes

\section{Normal values ${ }^{1}$}

\begin{tabular}{|l|l|l|}
\hline S.No & Test & Normal values \\
\hline 1. & TSH & $0.34-4.25 \mu \mathrm{IU} / \mathrm{ml}$ \\
\hline 2. & fT3 & $9.0-16 \mathrm{pmol} / \mathrm{L}$ \\
\hline 3. & T4 & $70-151 \mathrm{nmoL} / \mathrm{L}$ \\
\hline
\end{tabular}

\section{Observations}

Graph 1: Mean age

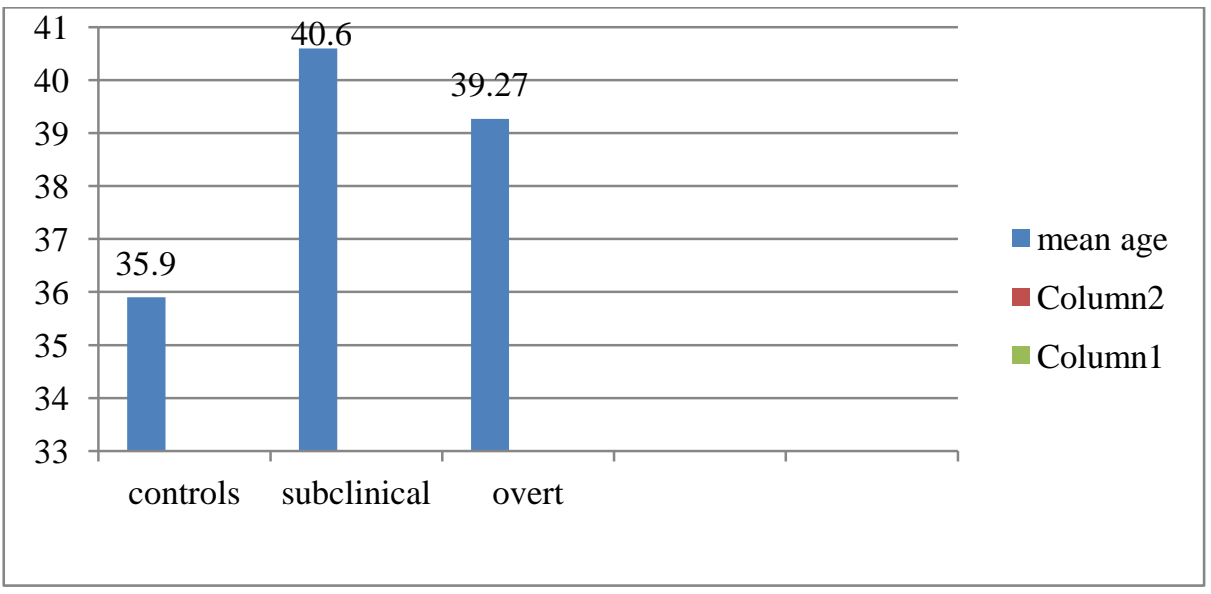

Graph 2: Sex distribution

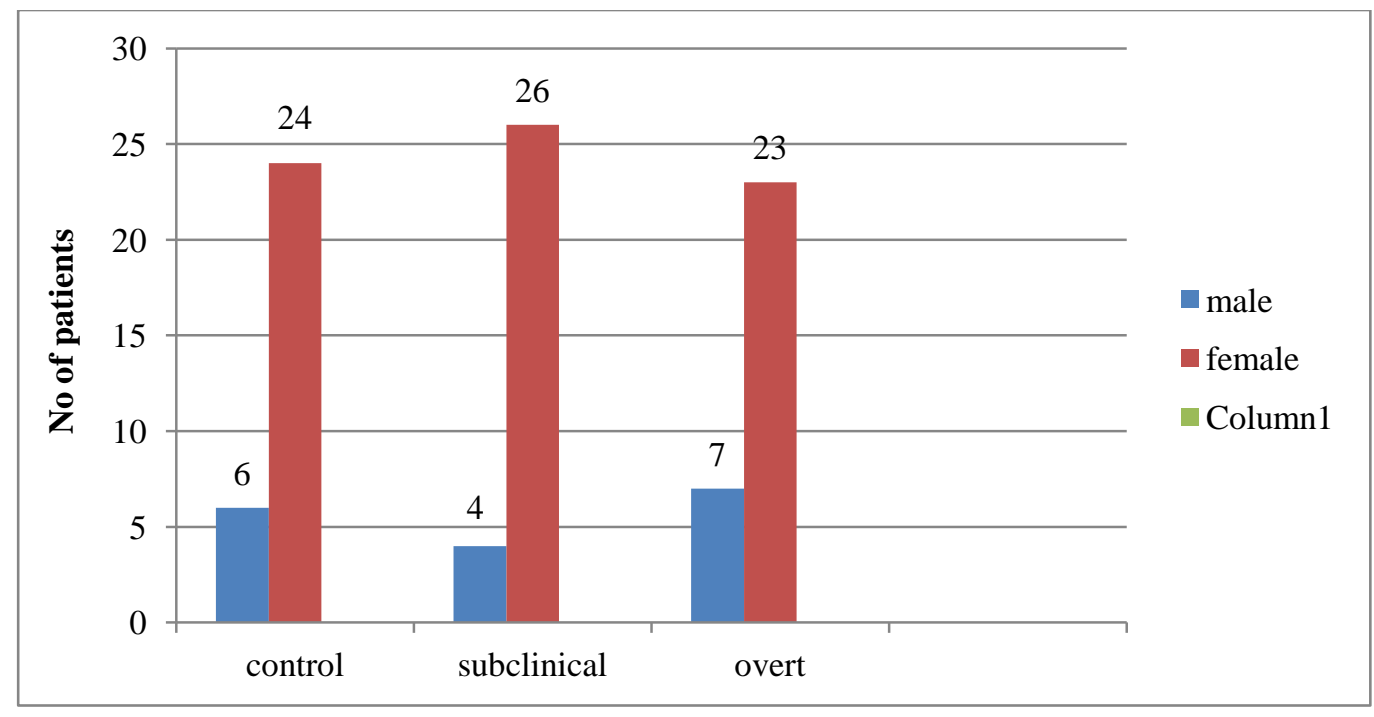




\section{JMSCR Vol||06||Issue||10||Page 814-818||October}

Table 1: Comparison of T3 T4 TSH above Conrtrols Subclinical and overt Hypoyhyrodism
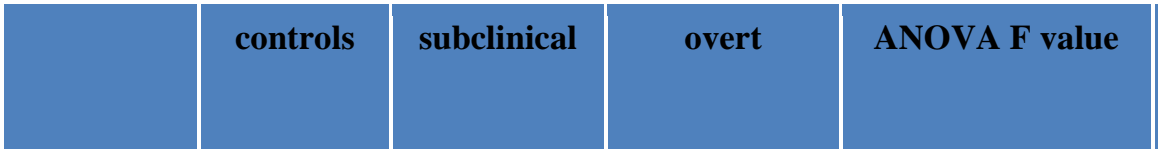

P Graph 3: MEAN CREATINE LEVEL IN DIFFERENT GROUP

\begin{tabular}{|r|}
\hline T3 \\
\hline T4 \\
\hline
\end{tabular}

$1.08 \pm .24$

$1.03 \pm .30$

$0.61 \pm .26$

26.587

$<0.001$

TSH

$8.21 \pm 1.96$

$7.75 \pm 1.77$

$2.91 \pm 1.98$

70.805

$<0.001$

$2.10 \pm 1.14$

$7.91 \pm 1.32$

$58.35 \pm 21.24$

189.602

$<0.001$

Graph 3: Mean Creatine Level in Different Group

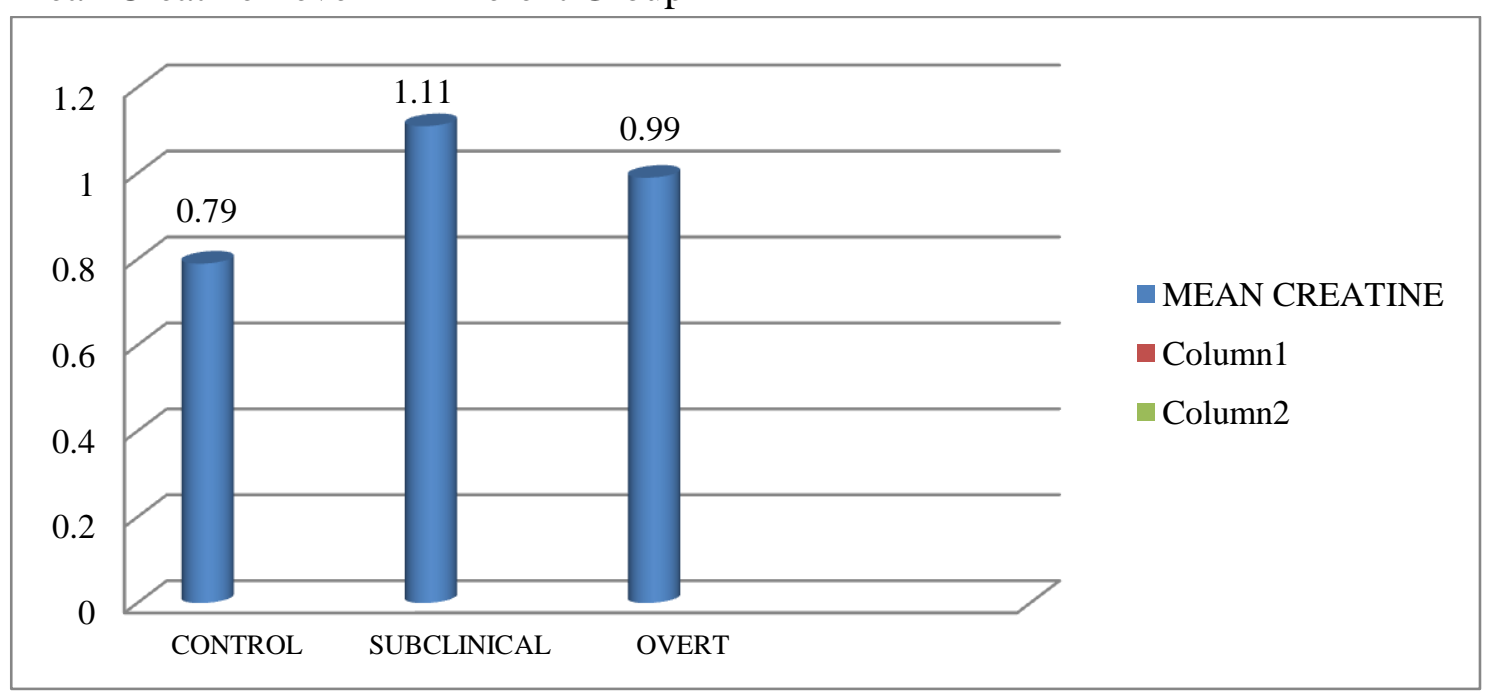

Graph 4: Distribution of Asymptomatic and Symptomatic Patients between the Groups

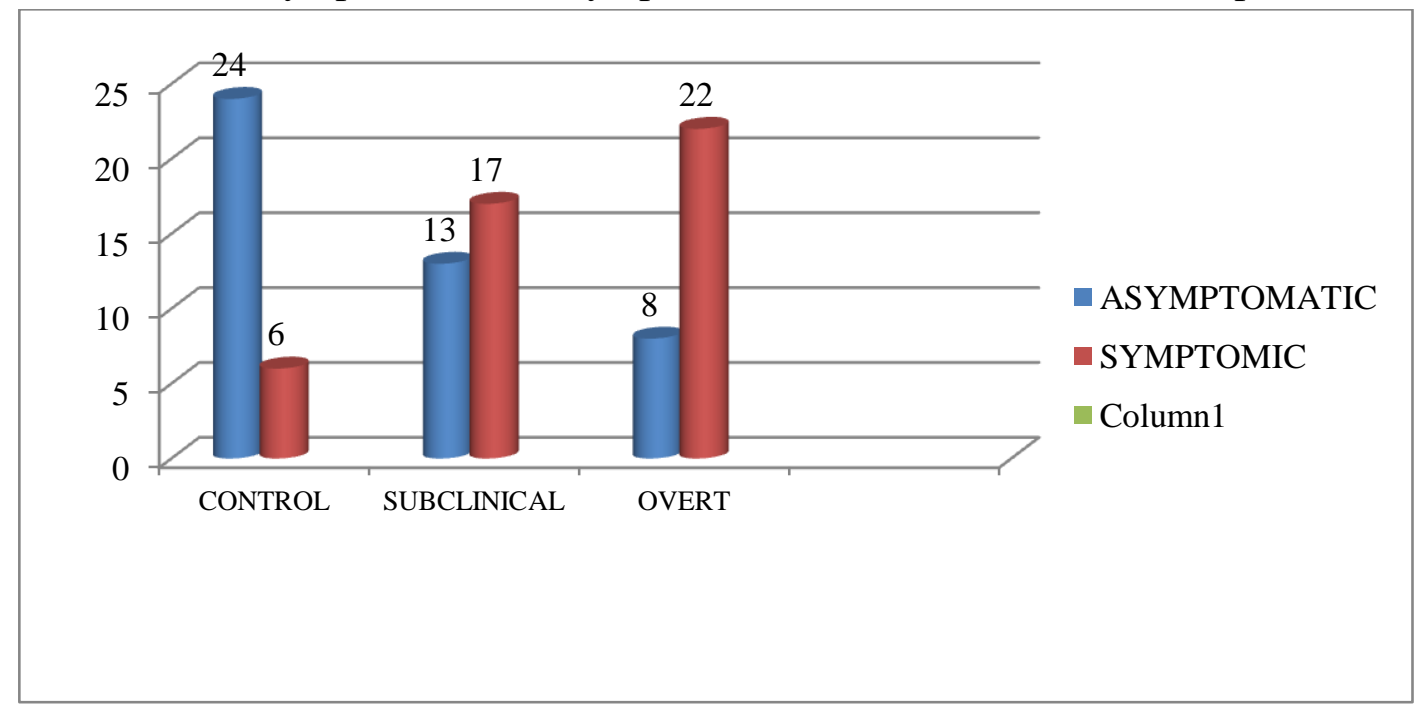

Table 2: Comparison of Normal and Abnormal CPK Values between Groups

\begin{tabular}{|l|c|c|c|}
\hline GROUP & CPK & & TOTAL \\
\hline CONTROL & NORMAL<170U/L & ELEVETED>170U/L & \\
\hline SUBCLINICAL & 19 & 0 & 30 \\
\hline OVERT & 5 & 11 & 30 \\
\hline
\end{tabular}


Graph 6: Comparison of Normal and Abnormal CPK values between Groups

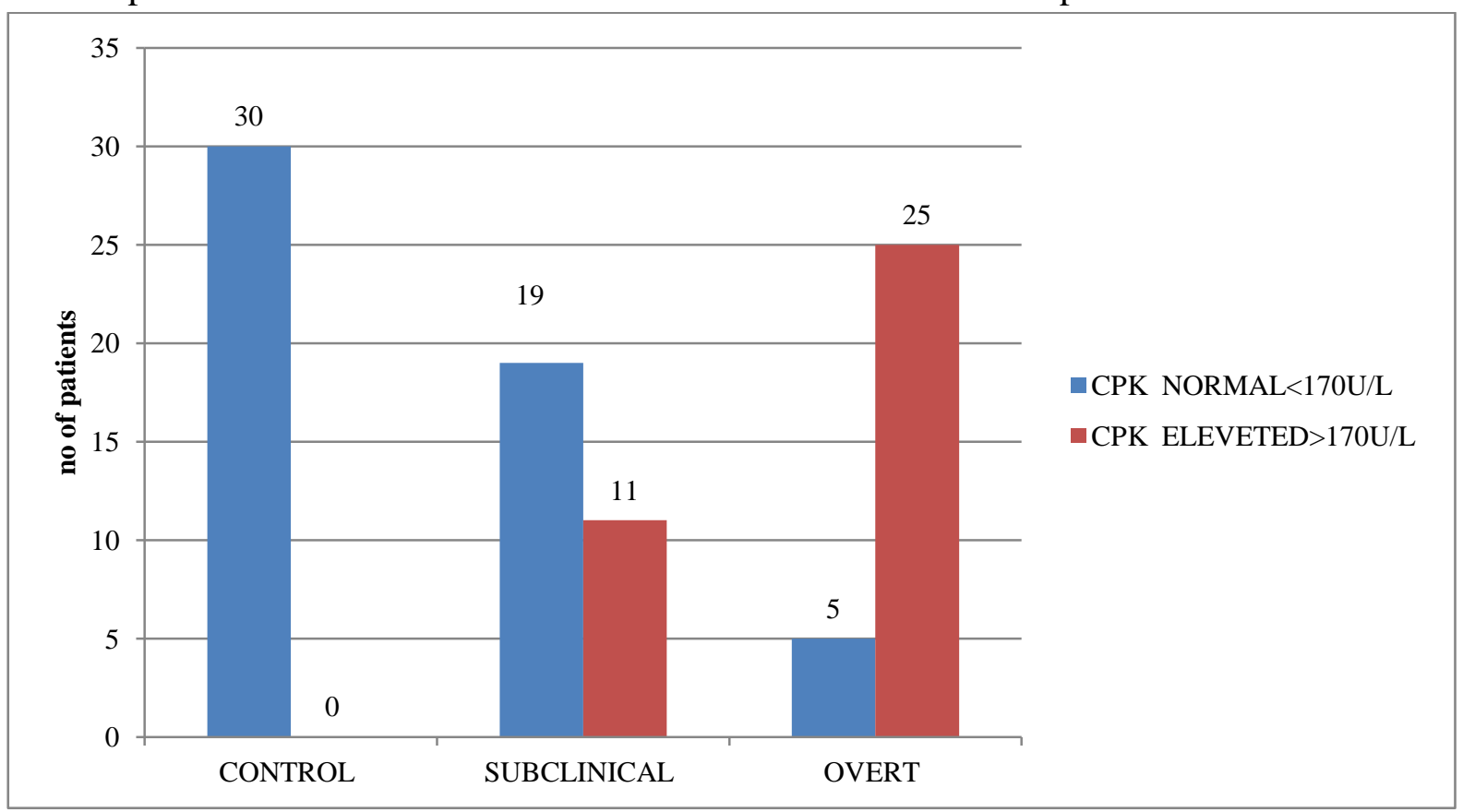

Table 3 Pearson correlation of T4 with Age, Weight, T3, TSH, Creatinine and CPK

\begin{tabular}{|l|c|c|}
\hline Parameter & Correlation-r -value & P- value \\
\hline T4 v/s age & -0.063 & 0.556 \\
\hline T4 v/s weight & -0.125 & 0.239 \\
\hline T4 v/s T3 & 0.639 & $<0.001$ \\
\hline T4 v/s TSH & -0.797 & $<0.001$ \\
\hline T4 v/s Creatinine & -0.085 & 0.428 \\
\hline T4 v/s CPK & -0.576 & $<0.001$ \\
\hline
\end{tabular}

\section{Discussion}

Hypothyroidism is a graded phenomenon, ranging from very mild cases with hardly no symptoms, to very serious case of life threatening myxoedema coma. The study shows that muscle dysfunction starts early even during subclinical hypothyroidism. There is not much difference between mean ages of all three groups that is in accordance with study done by Tayal D et $\mathrm{al}^{2}$. The distribution of sex shows increased no. of females in all groups that is in accordance with study by Sheikh et al ${ }^{3}$ and Ali $\mathrm{M} \mathrm{N}$ et al ${ }^{4}$ in their study on hypothyroidism.

The mean value of T3 and T4 in control and sub clinical hypothyroidism has not much difference which is in accordance with previous studies which states that in subclinical hypothyroidism, only TSH increases but level of T3 and T4 remains same.

The mean TSH value in overt hypothyroidism was 58.35+/-21.24 $\mu \mathrm{IU} / \mathrm{L}$ which was higher than control and subclinical hypothyroidism group and was highly significant According to study of Rodrigo $\mathrm{C}$ et $\mathrm{al}^{5}$ there are several case reports of acute renal failure in untreated hypothyroidism. When we compare level of serum creatinine between all group there is no much difference between control and hypothyroidism which is against the finding of study by Rodrigo $\mathrm{C}$ et $\mathrm{al}^{5}$. The study results show increased incidence of muscles symptoms in subclinical and overt hypothyroidism that is in accordance with study done by Fabio Monzani et $\mathrm{al}^{6}$. According to study of Prakash A et al ${ }^{7}$, hypothyroidism is common 
cause of an elevated creatine kinase in serum. The rise in CK activity is 4-6 folds higher in overt hypothyroidism cases as compared to control and subclinical hypothyroidism cases in the present study. Hekimsoy et $\mathrm{al}^{8}$ also reported the same. Ö Malley et $\mathrm{al}^{9}$ has reported that rise in CK is related to the sub normal body temperature accompanying primary hypothyroidism.

There is highly significant negative correlation between $\mathrm{T} 3$ and $\mathrm{T} 4$ with $\mathrm{CK}$ activity in the present study, indicative of predominant role of decreased T3 and T4 level in overt hypothyroidism in influencing the release of $\mathrm{CK}$ from skeletal muscle

\section{Conclusion}

The study shows that in both cases of hypothyroidism, TSH levels were increased but the level of T3 and T4 in majority of subclinical hypothyroids were normal.

The musculoskeletal system is frequently involved in hypothyroidism and is the one of the common cause for elevated total CPK activity in blood.

There was no significant difference in serum creatinine level in any groups.

The level of elevation of CPK activity is multiple times higher in overt hypothyroidism group as compared to subclinical hypothyroidism group.

There is highly significant negative correlation between T3, T4 and positive correlation of TSH with total CPK activity in this study indicating the decisive role of thyroid hormone on oxidative metabolism in muscle.

\section{Bibliography}

1. Kratz A, Pesce MA, Basner RC, Einstein AJ. Laboratory values of clinical importance. In: Kasper, Fauci, Hauser, Longo, Jameson and loscalzo editors. Harrison's Principles of Internal Medicine 19th edn. Newyork: McGraw Hill; 2015:

2. Tayal D Chawla R, Arora S et al. Dynamic changes in Biochemical Marker of renal function with thyroid status -A study in indian population .internet journal of medical update 2009;4(2):36-41

3. Sheikh BA, Soomro AA, Soomro MA, Pirzado ZA et al. Lipid profile in primary hypothyroidism at Chamdka Medical College Larkhana, Medical channel 2009;15(4);15-18

4. Ali MN ,Ibrahim AM,and Mohamad AB.Prevalance of Thyroid Dysfunction and its Effects on serum lipid profile in a Murzok Libya population .Thyroid science 2008;3(10):1-6

5. Rodrigo C, Gamakarazage C, Epa D S, Gnanathasan A, Rajapakse S. Hypothyroidism causing paralytic ileus and Acute Kidney Injury-case report, Thyroid research2011;4(7):1-4

6. Monzani F, Caraccio N . Del Guerra P, Casolaro A, Ferrannini E. Neuromuscular Symptoms and Dysfunction in subclinical Hypothyroidism patient: Beneficial effect on L-T4 replacement Theraphy. Clin Endocrinal 1999;51:237-242

7. Prakash A, Lal A K, Negi KS. Serum Creatine Kinase activity in Thyroid disorder .JK Science 2007;9(1):25-26

8. Hekimsoy Z, Oktem I K .Serum Creatine Kinase level in overt and subclinical Hypothyroidism .Endocr Res 2005;31 (3): $170-175$

9. Sterling $\mathrm{K}$, Lazarus JH, Milch PO .Mitochondrial thyroid Harmone receptor: Localization and Physiological Significance. Science 1978;201 (4361);1126-9. 